\title{
Editorial: Novel and Contemporary Perspectives in Medical Nutrition
}

\author{
Mark Lucock* $^{*}$ \\ School of Environmental \& Life Sciences, University of Newcastle, PO Box 127, Brush Rd, Ourimbah, NSW 2258, Australia
}

I was originally asked to put together a special issue for $E x$ ploratory Research and Hypothesis in Medicine (ERHM) on the topic of "Medical Nutrition". I scratched my head, and considered how far human nutritional sciences have evolved over the past two decades, and suggested to the Journal's editorial staff that an alternative theme- - "Novel and Contemporary Perspectives in Medical Nutrition"- might fit more comfortably with where the state of the art now resides.

This revised title appealed because it had a more contemporaneous perspective, encompassing a potential breadth of ideas from the role of maternal diet in early human development within the burgeoning field of "Developmental Origins of Adult Disease" through to the concept of "Functional Foods" and related bioactives in maintenance of human health. These and other concepts, such as "Personalized Nutrition", "Nutrigenetics/Nutrigenomics" and "Epigenetics", are cognate subdiciplines of human nutrition that have grown to become hugely significant in the modern era of "Molecular Nutrition". The goal was to have an issue that best reflects how nutrition now serves the prevailing paradigm(s) of what is meant by optimal human health.

The medical application of human nutrition has been a long and interesting journey. Hippocrates was born 2,500 years ago (460 BC) on Kos, and famously stated, "Let food be thy medicine and medicine be thy food". It seems appropriate to me that, as the "Father of Medicine", Hippocrates' rationalization/professionalization of the approach to treating disease advocated lifestyle approaches, such as exercise and diet, to treat pathology. Indeed, a lesser cited aphorism attributed to Hippocrates was "Walking is man's best medicine". I'm sure time has reshaped these much-quoted tenets that are as relevant today as they were two and a half millennia ago — and I'm happy to be a firm believer in the message they convey.

Although Hippocrates sagely advice was lost over the years, understanding the role of diet and health really ramped up in the early 1900s. Sir Frederick Gowland-Hopkins was awarded the Nobel Prize in Physiology of Medicine in 1929 along with the Dutch Physician Christiaan Eijkman. ${ }^{1}$ They received this preeminent award for the discovery of vitamins. However, this achievement should really also include the Polish biochemist Casimir Funk, who was another important architect in developing our understanding of micronutrients in the maintenance of human health. ${ }^{2}$

The first half of the twentieth century was devoted to curing deficiency syndromes - it was all about under-nutrition. In 1912, Gowland-Hopkins conducted seminal work, demonstrating that a

*Correspondence to: Mark Lucock, School of Environmental \& Life Sciences, University of Newcastle, PO Box 127, Brush Rd, Ourimbah, NSW 2258, Australia. Tel: +612 4348 4109, Fax:+61 24348 4145, E-mail: mark.lucock@newcastle.edu.au

How to cite this article: Lucock M. Editorial: Novel and Contemporary Perspectives in Medical Nutrition. Exploratory Research and Hypothesis in Medicine 2017;2(4):77-78. doi: 10.14218/ERHM.2017.EDITORIAL. highly refined diet comprised of pure proteins, carbohydrates, fats, minerals and water fail to support growth in weanling rats. This led him to discover that tiny quantities of an as yet unidentified dietary substance (from milk) was essential for animal growth and survival. These unidentified, speculative substances were, in 1913, given the name "vitamins" (from vital amines).

If the first half of the last century was about vitamin discovery and treating deficiency diseases like pellagra and beriberi, the second half of the twentieth century was all about addressing problems of over-consumption and the associated disease burden (increased obesity, type II diabetes, cardiovascular disease and cancers). Public health guidelines in the USA identified the issues and developed sound public health guidelines. In 1988, C Everett Koop, USA's Surgeon General, published a report that spawned further reports and recommendations. ${ }^{3}$ Basically, the nation had to face up to dietdisease associations linked to a diet high in saturated fatty acids, total fat, cholesterol, salt and sugars, but low in unsaturated fatty acids, complex carbohydrates and fiber. A diet that is basically high in animal products and which is largely energy rich-nutrient poor with too little plant-based materials.

However, over the last 20 years, with an increasingly affluent and aging society, concepts such as functional foods and use of supplements/nutraceuticals have come into favor to support health and the compression of morbidity. Academia and industry have developed synergies to develop this concept, and since the 1990s, scientists have been actively examining zoochemical and phytochemical bioactives as potential new agents to promote health, prevent disease and improve longevity.

One of the most interesting ideas in the field of phytochemical bioactives is that of xenohormesis: phytochemicals are produced by plants under stress, and when consumed, are able to activate longevity pathways in other organisms, including humans.

This special issue of ERHM examines many of these contemporary issues. Given the seemingly intractable problems society faces today, and even more so tomorrow in dealing with an ageing population structure (and the corollary of increased Alzheimer's disease, diabetes, cardiovascular disease, etc.), perhaps diet should be reexamined and framed once again as "Food is Medicine".

As an Associate Editor at ERHM, I'd like to thank all contributors to this issue, it has turned out to be a well-rounded selection of topics that deal with leading edge issues of huge relevance to society. Our contributors have dealt with many of the topics I have alluded to above: from xenohormesis to leading-edge research on the role of phytochemicals in pancreatic cancer cell models; from nutrition in sports injury to vitamins in depression. The articles also span the lifecycle from pediatric applications of enteral nutrition in Crohn's disease to vitamin genetics and cognitive decline in the elderly.

What goes 'round, comes 'round - time to return to food as medicine. 
Explor Res Hypothesis Med

\section{References}

[1] Thomas A. Who was Fredrick Gowland-Hopkins? The Biologist 2011; 58:33-37.

\author{
Lucock M.: Editorial
}

[2] Griminger P. Casimir Funk - A Biographical Sketch (1884-1967). J Nutr 1972;102:1105-1113.

[3] Surgeon General's Nutrition \& Health Report. Available from: https://www. c-span.org/video/?3713-1/surgeon-generals-nutrition-health-report.

Mark Lucock PhD, CBiol, FRSB, FRCPath

Mark Lucock 